\title{
Toward a Holistic Approach: Considerations for Improved Collaboration in Wildfire Management
}

\author{
Samantha J. De Abreu \\ School of Environmental and Forest Sciences, University of Washington, Seattle, USA \\ Email: sdeabreu@uw.edu
}

How to cite this paper: De Abreu, S. J. (2022). Toward a Holistic Approach: Considerations for Improved Collaboration in Wildfire Management. Open Journal of Forestry, 12, 107-121.

https://doi.org/10.4236/ojf.2022.121006

Received: November 16, 2021

Accepted: January 9, 2022

Published: January 12, 2022

Copyright $\odot 2022$ by author(s) and Scientific Research Publishing Inc. This work is licensed under the Creative Commons Attribution International License (CC BY 4.0).

http://creativecommons.org/licenses/by/4.0/

\begin{abstract}
State and Federal agencies in the United States manage wildland fires to minimize forest loss and reduce fire impacts on communities living near forests. Despite changes to policy that emphasize the importance of collaborative management with Tribes and local communities, stakeholders with place-based knowledge still have limited access to meaningful participation in policy development and management planning. These barriers contribute to the alienation of communities disproportionately burdened with the negative impacts of wildfire. Reduced community-level support and a lack of inclusive practices regarding place-based knowledge result in less robust management plans and poor ecological outcomes. These outcomes highlight the need for improved multi-stakeholder collaborations that holistically address interconnected management areas. In this paper, Federal wildfire policy development and implementation are assessed to identify barriers to collaborative management. An examination of multi-stakeholder fire management organizations showed that coupling of federal policy, practices and norms and the underrepresentation of external stakeholders may hinder progress toward collaborative partnerships. A linguistic examination of federal wildfire policy showed that directive, rather than cooperative language predominated. This may promote unequal power-sharing dynamics that reduce opportunities for federal engagement and collaboration with stakeholders from Tribes and local communities. Tribal barriers to equitable partnership and decision-making were found to be tied to culturally mediated frameworks for environmental management. Based on these findings, this article offers suggestions for changes to policy and institutional culture that will allow for an inclusive, holistic fire management model.
\end{abstract}

\section{Keywords}

Collaborative Land Management, Wildfire Policy, Stakeholder Engagement, 
Place-Based Knowledge, Indigenous Knowledge

\section{Wildland Fire Management Policy in the United States: A Brief Background}

Institutionalized wildland fire management policy in the United States dates to the formation of the United States Department of Agriculture Forest Service (USFS). Forest reserves were managed by the Department of the Interior prior to the Forest Transfer Act of 1905, when responsibility shifted to the United States Department of Agriculture (USDA) (Busenberg, 2004). During this time, these reserves-which would later become the National Forests-were rapidly expanded. Due to the increased timberland area to be managed, Congress passed an appropriations bill in 1908, providing the Forest Service with the financial means to pursue an aggressive fire suppression policy throughout the U.S. (Busenberg, 2004; Pyne, 1982). To carry out these operations, a cooperative network of fire management was formed, which included the USFS and other State and Federal agencies. In 1924, the Clark-McNary Act passed, allowing the USFS to work cooperatively to suppress fire on any forested land, even land not federally owned (Busenberg, 2004; Pyne, 1982). Further policy shifts, including the Federal Wildland Fire Management Policy of 1995, were enacted to direct and inform agency collaboration on fire management (USDA/DOI, 2009; USDOI, 1995). Wildland fire policy has evolved to encourage cooperative and collaborative efforts between government agencies and external stakeholders. State and Federal partnership with Tribes and local communities continue to be pursued, but policy alone has not ensured equitable partnership and decision-making. Top-down hierarchical dynamics, values differences between stakeholders, and lack of appropriate stakeholder engagement have been identified as contributing factors (Goldstein and Butler, 2010; Lake et al., 2017; Long and Lake, 2018; Steelman and Nowell, 2019). Further analysis is needed to identify additional variables contributing to institutional dysfunction in these areas. This is imperative given that existing management strategies continue to produce outcomes that perpetuate environmental problems and patterns of social-ecological inequity (Hessburg et al., 2021; Long and Lake, 2018; Schultz et al., 2019). Research on fire management continues to mention the importance of co-management with Indigenous communities, but often fails to address barriers to equitable partnership in these calls to action. In this study, the author examines wildfire management, policy, planning, and implementation to provide insight into barriers to cooperative fire management. Changes are suggested in policy development and stakeholder engagement to promote inclusive planning efforts. Institutionalization of Indigenous ecological frameworks and prioritization of Tribal stakeholders are suggested to reduce inequities to Tribal stakeholders in wildfire management. 


\section{Barriers to Collaborative Management}

\subsection{Inter-Agency Coordination Efforts: Who Gets a Seat at the Table?}

Federal efforts to promote cooperative fire management strategies through policy include the creation of several multi-stakeholder groups to coordinate interagency efforts and work with external agencies and stakeholders.

The National Wildfire Coordinating Group (NWCG) was established in 1976 through a memorandum of understanding between the Department of Interior (DOI) and the Department of Agriculture (USDA) (NWCG.gov). The NWCG was designed to coordinate fire management and fire management strategy and ensure the standardization of equipment and training across agencies (NWCG.gov). NWCG members include government agencies, The Intertribal Timber Council, International Association of Fire Chiefs, and the National Association of Foresters (Figure 1).

While the NWCG pursues collaborative fire management through training, strategy and implementation avenues, the Wildland Fire Leadership Council (WFLC) was established in 2002 by the Secretaries of Agriculture, the Interior, Defense, and Homeland Security to oversee, monitor, and coordinate implementation of federal fire policy (USDA/DOI Forests and Rangelands). NWCG membership includes subsidiary agencies under each branch of leadership (Agriculture, Interior, Defense, and Homeland Security). It also offers limited seats for state, Tribal, county, and municipal government representatives (Figure 2). The WFLC's efforts to achieve coordinated action resulted in a partnership between the U.S. Department of Agriculture (USDA) and the Department of the Interior (DOI) called "Forests and Rangelands". Forests and Rangelands provides policy compliant information on fire management to intergovernmental agencies and external partners (USDA/DOI Forests and Rangelands).

\begin{tabular}{|c|c|c|c|}
\hline \multicolumn{4}{|c|}{$\begin{array}{l}\text { National Wildfire Coordinating Group (NWCG) } \\
\qquad \text { Established } 1976\end{array}$} \\
\hline \multicolumn{3}{|c|}{ Federal Agencies } & n-Federal Agencies \\
\hline $\mathrm{BIA}(\mathrm{DOI})$ & BLM (DOI) & USFS (USDA) & $\begin{array}{c}\text { Intertribal Timber } \\
\text { Council }\end{array}$ \\
\hline $\begin{array}{c}\text { Office of Wildland } \\
\text { Fire (DOI) }\end{array}$ & $\begin{array}{c}\text { Fish and Wildlife } \\
\text { (DOI) }\end{array}$ & $\begin{array}{l}\text { US Fire Admin } \\
\text { (FEMA) }\end{array}$ & $\begin{array}{c}\text { Nat'l Assoc. State } \\
\text { Foresters }\end{array}$ \\
\hline $\begin{array}{l}\text { National Park } \\
\text { Service (DOI) }\end{array}$ & $\begin{array}{l}\text { National Weather } \\
\text { Service (NOAA) }\end{array}$ & & $\begin{array}{c}\text { Int'l Association of } \\
\text { Fire Chiefs }\end{array}$ \\
\hline
\end{tabular}

Figure 1. National wildfire coordinating group membership. 


\title{
Wildland Fire Leadership Council \\ Established 2002
}

\author{
Mission: Coordination, Monitoring and Implementation of Federal \\ Wildland Fire Policy
}

Federal Seats

\begin{tabular}{|c|c|}
\hline $\begin{array}{l}\text { Department of Defense: } \\
\text { Asst Secretary Energy, } \\
\text { Installations \& } \\
\text { Environment; } \\
\text { Deputy Assistant } \\
\text { Secretary for Homeland } \\
\text { Defense Integration and } \\
\text { Defense Support of Civil } \\
\text { Authorities }\end{array}$ & $\begin{array}{l}\text { Department of Agriculture: } \\
\text { Under Secretary for Natural } \\
\text { Resources and } \\
\text { Environment; Under } \\
\text { Secretary for Natural } \\
\text { Resources and } \\
\text { Environment, and the Chief } \\
\text { of the U.S. Forest Service }\end{array}$ \\
\hline $\begin{array}{l}\text { Department of Interior: } \\
\text { Directors of Bureau of } \\
\text { Land Management, US } \\
\text { Fish and Wildlife, Bureau } \\
\text { of Indian Affairs, } \\
\text { National Park Service, } \\
\text { and US Geological Survey }\end{array}$ & $\begin{array}{l}\text { Department of Homeland } \\
\text { Security: Fire } \\
\text { Administrator; U.S. Fire } \\
\text { Administration }\end{array}$ \\
\hline
\end{tabular}

Non-Federal Seats

\section{A governor who is a member of the National Governors Association \\ A county commissioner who is a member of the National Association of Counties;}

A mayor who is a member of the National League of Cities
A governor who is a from

The President of the Intertribal Timber Council request of his or her senior elected official the Western United States

A state forester at the

a fire chief of a state or any political subdivision thereof, at the request of his or her senior elected official.

Figure 2. Organizational structure of the wildland fire leadership council.

The Fire Learning Network (FLN) is another cooperative fire management organization established in 2002. This partnership included the Nature Conservancy, the DOI, and the USFS. While the NWCG and the WFLC address operation and policy-level aspects of coordinated fire management, the FLN emphasizes the importance of relationships and connection between coordinating agencies, local communities, and stakeholders. The goal of the FLN is facilitation of landscape-scale planning for fire-adapted ecosystems through collaborative learning, networking, and education (Goldstein and Butler, 2010).

Coordination and collaboration between managing agencies and external stakeholders are vital for addressing environmental and social targets of fire management but realizing these goals in an effective manner has been elusive. Multi-stakeholder groups involving federal agencies and policy have suffered from the rigidity and hierarchical structures characteristic of government organizations (Goldstein and Butler, 2010). Figure 1 and Figure 2 show that federal agencies are overrepresented in these alliances, while Tribes and local communities are underrepresented. The policy development, oversight and implementation carried out by these groups further couples them to federal influence. Power imbalances are the unintentional yet predictable result of a top-down structuration. This perpetuates a system where it remains challenging for diverse stakeholders to impact institutional culture and policy despite targeted federal attempts at equitable partnership. 


\subsection{Policy Development: Who Makes up the Rules?}

The limited representation of Tribal and community-level stakeholders in federally established organizations for cooperative wildfire management impacts the ability for institutional change to occur, as they are also charged with development and revision of policy. Tribal and community participation has been even more limited in policy development occurring outside of the oversight of these groups. In 2001, the National Fire Plan was developed by the secretaries of Agriculture and the interior to provide guidance on inter-agency cooperation to reduce fire risk for rural communities, restore the health of fire-adapted ecosystems, and ensure firefighting capacity for the future (USDA, 2001). The plan was developed in response to severe wildfire events precipitated by fire exclusion policies enacted 100 years earlier (Goldstein and Butler, 2010). The scientific community began to recognize that these policies had degraded the resilience of fire-prone ecosystems over time by removing the high-frequency, low-severity fires that naturally reduce fuel accumulation in these ecosystems (Hagmann et al., 2021). Indigenous fire management, which had been practiced for thousands of years prior to European contact (Marchand et al., 2020; Pyne, 1982), began to receive acknowledgement for the environmental benefits it conferred. These factors coupled with the success of Tribes fighting for partnership and inclusion in environmental decision-making and management saw wildfire policy shift toward a collaborative vision (Goldstein and Butler, 2010).

In addition to the need for better stakeholder collaboration formally incorporated into the National Fire Plan, the Secretaries of Agriculture and the Interior prompted a review of the 1995 Federal Wildland Fire Management Policy in 2001 and established the interagency Federal Wildland Fire Policy Review Working Group to review and update it (USDA, 2001). This process resulted in fundamental changes to philosophical and policy aspects of federal fire management. The updated policy addresses the complexity of fire management at the Wildland Urban Interface (WUI) where human development and wilderness meet, and includes directives that emphasize ecosystem sustainability, science, education, and communication (USDA, 2001). The Federal Wildland Fire Policy Review Working Group was comprised of agencies and their representatives that had originally worked to develop the 1995 Federal Wildland Fire Management Policy. The group was comprised of federal agencies and co-chaired by the USFS and the DOI. Non-government input was solicited in 2001 which had not occurred in 1995 by including the National Association of State Foresters. Tribal organizations and managers were not prioritized in the process. Confusion over implementation of these updates ensued, and a failure to include greater representation of diverse stakeholders in the policy development process may have been a contributing factor. Schultz et al. (2019) noted that goal ambiguity in the 2001 policy resulted in confusion about how to manage for multiple competing goals. The NWCG and WFLC requested the publication of an additional guide written in 2009 called "Guidance for Implementation of Federal Wildland Fire 
Management Policy" to help address the situation. This guide outlines processes for collaborative management between agencies, increased accountability, standardization of methods, and increased communication with non-federal stakeholders (USDA/DOI, 2009).

In 2010, a DOI and related agencies appropriations act called for development of a cohesive wildland fire management strategy in response to the passage of the Federal Land Assistance, Management, and Enhancement Act of 2009 (FLAME Act), which addressed funding for catastrophic wildfires (USDA/DOI Forests and Rangelands; USDA/DOI, 2014). The WFLC was responsible for appointing a Wildland Fire Executive Council (WFEC) to oversee the development of the strategy. Members of the WFEC included representatives from 6 government agencies in addition to the NWCG itself, the National Association of State Foresters (NASF), the International Association of Fire Chiefs (IAFC), and the Intertribal Timber Council (ITC), (USDA/DOI Forests and Rangelands). A Cohesive Strategy Subcommittee (CSSC), Three Regional Strategy Committees from the Eastern, Southern and Western regions of the U.S., and a National Science and Analysis Team worked with the WFEC and WFLC to develop the National Cohesive Wildland Fire Management Strategy, also known as the Cohesive Strategy. The Cohesive Strategy was created in a three-part process and was completed in 2014 (USDA/DOI Forests and Rangelands; USDA/DOI, 2014).

While the Cohesive Strategy significantly increased collaboration and participation of non-government stakeholders in policy development and implementation, Government stakeholders were still the primary source of input for strategic development, and equitable collaboration has not been achieved. Steelman and Nowell (2019) assessed wildfire response metrics of the Cohesive Strategy and found that power differentials still impacted collaboration between Incident Management Teams and local communities. They argued for joint involvement in decision making and involvement beyond "Informing and acknowledging" local jurisdictions. Also noted was the need for contextualizing response to the local area, and incorporating local values (Steelman and Nowell, 2019).

\subsection{Why Details Matter: Collaborative vs. Directive Language in Policy}

The language of wildland fire policy presents another challenge to collaborative management initiatives, promoting top-down hierarchical practices that hamper interactions between government agencies and community stakeholders. Steelman and Nowell's observations that local jurisdictions are informed and acknowledged rather than partnered with equitably are common outcomes that plague collaborative efforts arising from federal policy. The lack of power-sharing in the policy development process may have the unintended impact of producing policy directives and outcomes that closely conform to the top-down power structures prevalent in government agencies. These features can be observed in the language of wildland fire policy. In the 2001 Federal Wildland Fire Manage- 
ment Policy Update and the 2009 Guidance for implementation, terms used to describe cooperation and involvement with non-agency stakeholders represent a unidirectional approach to communication. For example, the 2001 policy update addresses communication as follows:

"Agencies will enhance knowledge and understanding of wildland fire management policies and practices through internal and external communication and education programs" (USDA, 2001).

This language is directive rather than cooperative, echoing the "informing and acknowledging" practices that persist in implementation of the Cohesive Strategy today (Steelman and Nowell, 2019). The communication and education described are aimed at reinforcing the policies and practices already in place rather than interacting with stakeholders in a participatory manner that could build relationships and strengthen fire management practices. The language regarding input for updating and guiding the Fire Management Policy's evolution through time also excludes contributions from community stakeholders with valuable place-based knowledge. This piece is written as follows:

"Fire management plans and programs will be based on a foundation of sound science. Research will support ongoing efforts to increase our scientific knowledge of biological, physical, and sociological factors. Information needed to support fire management will be developed through an integrated interagency fire science program" (USDA, 2001).

Sociological factors are to be pursued via scientific research under this policy, leaving out opportunities for gathering local knowledge via community engagement. Tribal knowledge is missing from this directive, which could benefit planning and programming efforts. The updated 2009 Guidance directive contains unidirectional language regarding public engagement as well, discussing collaborative efforts as "building and developing understanding with the public" with respect to fire management policies and practices (USDA/DOI, 2009). Like the other examples cited, this language fails to emphasize direct, meaningful exchanges with local stakeholders.

While the USFS has directives to engage the public in land management planning, the expectations are flexible enough that there are many variations in achieving public input and collaboration. For this reason, community and stakeholder participation varies with locale and leadership. The National Forest Management Act of 1976 required the Forest Service to develop land management planning and revision rules (NWCG.gov). For many years the planning rules were primarily updated through scientific input, but Tribal input was included in the 2012 Planning Rule after a series of national and regional roundtable discussions where the USFS sought public feedback (USFS, 2011). Changes to the 2012 rule were designed to eliminate some of the challenges that earlier versions faced, particularly the complex and drawn-out processes for public input that had been previously utilized. Another stated goal of the 2012 Planning Rule was to "Provide for a transparent, collaborative process that allows effective public participation" (USFS, 2011). While these changes helped improve the process by in- 
cluding a period of public input, and local determination of how to engage the public, the results of these policies on meaningful public participation should be researched further.

The Cohesive Strategy is another policy that sought increase collaborative efforts but suffers from the linguistic traps that ensnared its predecessors which may explain some of the challenges described by Steelman and Nowell (2019). The Communication Framework Published in 2011 described the collaborative piece of the communication strategy as follows, echoing the directives to develop and implement the policy:

"Organizational Communication and Collaboration: Facilitate development and implementation of organizational communication processes that enhance and sustain collaboration among stakeholders toward development and implementation of the Cohesive Strategy."

While focus on policy implementation as the goal for collaboration is of potential concern, the inclusion of language directly emphasizing stakeholder collaboration in this passage may provide hope toward increased participatory practices, however, further research should be undertaken to explore how it is impacting collaborative practices and management outcomes.

\subsection{Organizational Culture and Tribal Partnership}

The problems created by failing to prioritize Tribes and community stakeholders in policy development and properly engage them in collaborative planning efforts may be compounded by challenges associated with the transmission of hierarchical values and Western culture through federal organizations and processes under federal oversight.

Relational dynamics espoused in policy directives result in the devaluing of the ecosystem knowledge and fire management strategies of Tribes and local communities. Their experiences are often excluded or seen as less important than information arising from agency scientists (Long and Lake, 2018). Research and management strategies that fail to engage those with place-based environmental knowledge can produce outcomes that are both socially and ecologically harmful. A failure to appropriately engage stakeholders living near state and federal management areas can lead to misunderstanding, distrust, and resentment of land management policy, particularly for communities that have already experienced harm at the hands of outside decision makers (Cochran et al., 2008; Hessburg et al., 2021). The Northwest Forest Plan is one example of well-intended environmental policy that failed to meet key social and ecological goals due to inadequate public engagement and the resultant alienation of communities living in the management area (Franklin and Johnson, 2014; Long and Lake, 2018).

Existing management plans developed with little community input can conflict with the interests and values of local stakeholders and perpetuate systemic inequities. For example, the Federal Wildland Fire Management Policy of 1995/2001 places human life and public safety as the top priority for fire suppression, with 
resources and property as the second priority. This latter category is decided based on the value of the resources. However, human and community structures are generally protected above timber and other ecosystem resources regardless of value difference (Bayham and Yoder, 2020; USDA, 2001). Valuation of resources is culturally mediated (Cochran et al., 2008), but Western fiscal approaches are used as a default because culture is only tangentially addressed in policy, rather than holistically incorporated. This is an unintended outcome of policy development practices that don't incorporate diverse perspectives.

Tribes are disadvantaged by fire management policy and practices because their community needs and cultural resource valuations diverge from Western cultural conceptions (Cochran et al., 2008). One example of this is the 2015 Cougar Creek Fire which burned 41,500 acres of Yakama Tribal forest, over 20\% of their commercial timber land (Knauf, 2015). Tribal leaders and land managers were frustrated because dispersed fires throughout the state resulted in firefighting resource limitation during that fire season and resources were diverted from the reservation to areas around Lake Chelan where people had built expensive vacation homes in an area of fire risk (Knauf, 2015). The Tribe had specifically chosen not to build homes in forested areas, and because of this decision they ended up losing more economic value in timber than community members nearby who built homes in fire-prone areas. These structures were saved instead of Tribal resources despite the homes being unoccupied during the fire.

Tribes and local stakeholders with non-dominant value systems may also be unintentionally constrained and marginalized in fire management collaborations because government institutions lack a framework to holistically understand and incorporate alternative epistemologies beyond Western Science. Fire management has continued evolving toward a more scientific lens through time. While foresters and land managers of the past were seen as subject-matter experts for their place-based knowledge, modern policy and management emphasizes the value of science. Today, Tribes, foresters, and land managers are expected to use a scientific lens for inquiry, assessment, and problem solving. Using scientific input in fire management planning is also canonized in policy, being one of the major tenets of the Federal Wildland Fire Management Policy (USDA, 2001), as well as the Cohesive Strategy (USDA/DOI, 2014).

Science is a valuable tool for environmental management, but it should not be the only tool utilized when managing complex social-ecological systems. Relying on scientific methods alone for ecosystem management has many drawbacks, particularly where social-ecological systems and disturbance are concerned. Studies and prescriptions disconnected from the management areas can result in pervasive environmental problems (Holling and Meffe, 1996). Large management areas with high levels of variation and environmental processes that occur over protracted timescales pose a challenge to methods that operate on fine temporal and spatial scales. Fire events have been particularly difficult to develop accurate predictive models for due to these reasons (Tardivo et al., 2017). 
Fire-or lack thereof-also has legacies that can last centuries, far longer than most studies are capable of monitoring (DeLuca et al., 2006; Zackrisson et al., 1996). These struggles are compounded by excluding input from stakeholders like Tribes that practice long-term monitoring and cultural transmission of environmental knowledge. While many studies advocate for co-management with Indigenous communities today, the failure for critical reflection on the role of culture in management policy and practices has meant that Indigenous epistemologies still struggle to achieve institutional acceptance and legitimacy.

Indigenous Ways of Knowing (IWK) represent a holistic framework for Indigenous knowledge formation and a body of knowledge that emphasizes connections and are used by Indigenous people to holistically understand the world (Berkes, 2009). IWK can produce robust solutions when dealing with high levels of environmental complexity and variability in a way that Western science struggles to achieve (Berkes and Berkes, 2009). Tribal land managers frequently pair IWK with Western science to achieve holistic outcomes. Tribes also continuously monitor system changes over time and compare with historical conditions because of the practice of passing down knowledge, combined with the proximity of Tribal communities and managers to the management area (Berkes and Berkes, 2009; Kimmerer, 2002). These practices of monitoring and adaptation allow Tribes to achieve ecological resilience on their managed lands. The importance of transgenerational management and monitoring for fire management has been emphasized in recent scholarship by Hessburg et al. (2021).

\section{Discussion}

Deciding how to incorporate stakeholder knowledge and balance competing objectives is not straightforward. Incorporating stakeholder knowledge into resource management planning can produce robust and holistic plans, but also involves increased complexity (Gray et al., 2012).

Despite these considerations, change is necessary. The top-down decision-making that pervades government agencies has had devastating social, economic, and ecological consequences. These practices have placed stakeholders and management agencies at odds, with lasting consequences for ecological sustainability (Holling and Meffe, 1996; Long and Lake, 2018). Corburn (2003) asserts that local communities who face the risk of planning decisions should never be ignored, citing the valuable local knowledge they contribute to political and technical aspects of planning efforts. This knowledge could enable decision-makers to develop robust management plans with the support of the local community, avoiding pitfalls of policy like the Northwest Forest Plan. For these reasons, wildfire management must become a reciprocal knowledge building process. To achieve this goal, policy development and multi-stakeholder organizations must continue evolving to address power differentials and increase meaningful community-level participation in decision-making. Efforts like the FLN that emphasize relationships and networking have shown more promise than organiza- 
tions like the NWCG and the WFLC which are more tightly coupled to the organizational structure of government institutions (Goldstein and Butler, 2010). Language should be carefully chosen in policy to avoid non-collaborative messages. Policy directives that include information exchange and power-sharing between government agencies and local communities may address some of the existing challenges inherent in these undertakings.

Equitable social-ecological outcomes will require targeted effort to prioritize those with the intimate knowledge of the land who are most impacted by land management decisions. There is ample scholarship showing that Tribal perspectives on managing fire-prone ecosystems are needed. Tribes have fought for inclusion in policy development and land management, successfully forming alliances with diverse stakeholders to achieve these goals. While policy has shifted to increase opportunities for Tribal inclusion in land management, work needs to be done by non-Tribal agencies and institutions to increase understanding and respect for Indigenous cultural values and frameworks for forming ecological knowledge like IWK. Tribes rely heavily on the land for cultural, spiritual, and economic survival, so land management decisions often impact them in a way that other stakeholders do not experience. For these reasons, common means of assigning value to property during a fire event have perpetuated the systemic marginalization of Tribal communities (Knauf, 2015; Lake et al., 2017). These outcomes highlight the need for deep reflection on the role of culture in environmental policy and management.

Figure 3 is a graphic showing guidelines that federal and state agencies could

\section{Guidelines for Weighting Stakeholder Priority in Fire Management}

Low Priority

High Priority

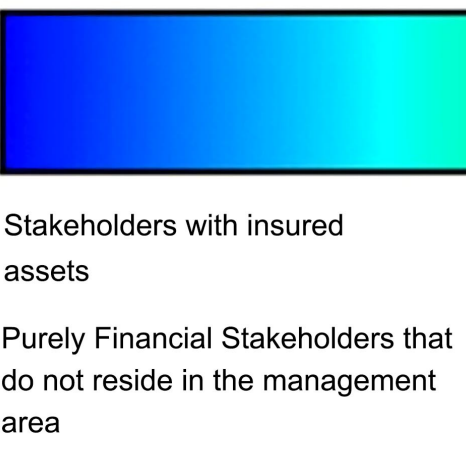
Newer residents to the area
Purely Financial Stakeholders and stakeholders with insured assets that may not reside in the management area but have conducted business there for an extended period of time
People whose assets and income exceed a predesignated limit that would allow them to replace the loss of property Stakeholders that have
individually or as a group
lived as a resident in the
management area for an
extended time period
Stakeholders from
economically disadvantaged
and/or culturally
underrepresented groups
Stakeholders from groups
indigenous to the region

Figure 3. Guidelines for prioritizing stakeholder engagement in wildfire management. 
use to prioritize stakeholder engagement. While this graphic does not account for some of the concerns that might be present in each management area due to potential differences in environment, land ownership, community, and socio-political landscape, regional tailoring would allow these guidelines to be a starting point for collaborative decision-making. They could be particularly useful for management plan modeling such as the Analytic Hierarchy Process to assign weights to stakeholder preferences (Ananda and Herath, 2003).

Cultural change that promotes equity for Tribes is vital for the implementation of socially just planning frameworks. Policies that glorify Western Science and ignore IWK create barriers that are often overlooked. To enact lasting change, the Institutionalization of Indigenous frameworks in the U.S. is a necessary step. As described by Meyer and Rowan (1977), institutionalization is the process through which things gain a rule-like status in social thought and action. In the modern era, science is institutionalized in Western thought, policy, and practice, which is why its inclusion in K-12 education and fire management policy is taken for granted, rather than contested. According to Meyer and Rowan:

"Organizations are driven to incorporate the practices and procedures defined by prevailing rationalized concepts of organizational work and institutionalized in society. Organizations that do so increase their legitimacy and their survival prospects, independent of the immediate efficacy of the acquired practices and procedures" (1977).

Using institutional theory, IWK and Tribal fire management practices can gain legitimacy and institutionalization by developing a formal structure that adheres to the notions of existing organizations. Education and changes to policy are potential entry-points for this to occur. Methods and guidelines to incorporate Indigenous knowledge into systems based on scientific-based ecological knowledge (SEK) developed by Tribal elders and members of the scientific community provide a pathway for IWK to gain legitimacy as an institution in the U.S. (Lake et al., 2017; Mason et al., 2012). Recommendations include development of a national program for education on IWK and SEK, workshops by keepers of IWK to inform and educate land managers, and improved partnership and collaboration between educators, scientists, and managers to promote cross cultural exchanges. Pat Pierre, Salish-Pend d'Orielle elder in attendance, stated that the overarching goals should be "a simple prescription for cross-cultural progress: open communication, education, respect, and friendliness" (Mason et al., 2012). The development of a national platform like this could allow IWK to gain legitimacy in the mainstream public, particularly if it is incorporated into $\mathrm{K}-12$ education and taught alongside SEK.

\section{Conclusion}

Achieving equitable collaboration between government organizations and external stakeholders in wildfire management has been elusive. Despite attempts to shift policy, institutional rigidity has resulted in less than desirable outcomes 
that do not allow for meaningful participation for many stakeholders. Tribal communities may be especially disadvantaged by the lack of power-sharing opportunities available in existing collaborative processes. Improved communication and collaboration with local communities and Tribes are key for developing socially just and environmentally sustainable fire-management policy. Policy development must become a bottom-up rather than top-down process, and policy created must include clear language to reduce harmful power differentials that have persisted for decades. Ongoing monitoring, assessment, and evolution of policy outcomes on collaborative practices should be undertaken to ensure that progress is made. Additionally, the cultural practices of land management and policy must shift to be more inclusive through development of a holistic framework that can encompass multiple epistemologies on the environment, and compliment Western science with IWK and place-based knowledge. Education initiatives provide opportunity for lasting institutional transformation by promoting the value of IWK and place-based knowledge. Together, these institutional changes to fire management in the United States have the capacity to allow for development of robust management plans that promote sustainable and resilient forests for the future.

\section{Conflicts of Interest}

The author declares no conflicts of interest regarding the publication of this paper.

\section{References}

Ananda, J., \& Herath, G. (2003). The use of Analytic Hierarchy Process to Incorporate Stakeholder Preferences into Regional Forest Planning. Forest Policy and Economics, 5, 13-26. https://doi.org/10.1016/S1389-9341(02)00043-6

Bayham, J., \& Yoder, J. K., (2020). Resource Allocation under Fire. Land Economics, 96, 92-110. https://doi.org/10.3368/le.96.1.92

Berkes, F. (2009). Indigenous Ways of Knowing and the Study of Environmental Change. Journal of the Royal Society of New Zealand, 39, 151-156. https://doi.org/10.1080/03014220909510568

Berkes, F., \& Berkes, M. K. (2009). Ecological Complexity, Fuzzy Logic, and Holism in Indigenous Knowledge. Futures, 41, 6-12. https://doi.org/10.1016/j.futures.2008.07.003

Busenberg, G. (2004). Wildfire Management in the United States: The Evolution of a Policy Failure. Review of Policy Research, 21, 145-156. https://doi.org/10.1111/j.1541-1338.2004.00066.x

Cochran, P. A., Marshall, C. A., Garcia-Downing, C., Kendall, E., Cook, D., McCubbin, L., \& Gover, R. M. S. (2008). Indigenous Ways of Knowing: Implications for Participatory Research and Community. American Journal of Public Health, 98, 22-27. https://doi.org/10.2105/AJPH.2006.093641

Corburn, J. (2003). Bringing Local Knowledge into Environmental Decision Making: Improving Urban Planning for Communities at Risk. Journal of Planning Education and Research, 22, 420-433. https://doi.org/10.1177/0739456X03022004008

DeLuca, T. H., MacKenzie, M. D., Gundale, M. J., \& Holben, W. E. (2006). Wild- 
fire-Produced Charcoal Directly Influences Nitrogen Cycling in Ponderosa Pine Forests. Soil Science Society of America Journal, 70, 448-453.

https://doi.org/10.2136/sssaj2005.0096

Franklin, J. F., \& Johnson, K. N. (2014). Lessons in Policy Implementation from Experiences with the Northwest Forest Plan, USA. Biodiversity and Conservation, 23, 3607-3613. https://doi.org/10.1007/s10531-014-0789-0

Goldstein, B. E., \& Butler, W. H. (2010). Expanding the Scope and Impact of Collaborative Planning: Combining Multi-Stakeholder Collaboration and Communities of Practice in a Learning Network. Journal of the American Planning Association, 76, 238-249. https://doi.org/10.1080/01944361003646463

Gray, S., Chan, A., Clark, D., \& Jordan, R. (2012). Modeling the Integration of Stakeholder knowledge in Social-Ecological Decision-Making: Benefits and Limitations to Knowledge Diversity. Ecological Modelling, 229, 88-96.

https://doi.org/10.1016/j.ecolmodel.2011.09.011

Hagmann, R. K., Hessburg, P. F., Prichard, S. J., Povak, N. A., Brown, P. M., Fulé, P. Z. et al. (2021). Evidence for Widespread Changes in the Structure, Composition, and Fire Regimes of Western North American forests. Ecological Applications, 31, e02431. https://doi.org/10.1002/eap.2431

Hessburg, P. F., Prichard, S. J., Hagmann, R. K., Povak, N. A., \& Lake, F. K. (2021). Wildfire and Climate Change Adaptation of Western North American Forests: A Case for Intentional Management. Ecological applications, 31, e02432. https://doi.org/10.1002/eap.2432

Holling, C. S. \& Meffe, G. K. (1996). Command and Control and the Pathology of Natural Resource Management. Conservation Biology, 10, 328-337. https://doi.org/10.1046/j.1523-1739.1996.10020328.x

Kimmerer, R. W. (2002). Weaving Traditional Ecological Knowledge into Biological Education: A Call to Action. BioScience, 52, 432-438. https://doi.org/10.1641/0006-3568(2002)052[0432:WTEKIB]2.0.CO;2

Knauf, A. (2015, October 27). When Firefighting Resources Are Thin, Reservations Are Left to Burn. The Seattle Globalist. https://www.seattleglobalist.com/2015/10/27/firefighting-resources-washington-wildfir es-yakama-colville-reservations-burn/43241

Lake, F. K., Wright, V., Morgan, P., McFadzen, M., McWethy, D., \& Stevens-Rumann, C. (2017). Returning Fire to the Land: Celebrating Traditional Knowledge and Fire. Journal of Forestry, 115, 343-353. https://doi.org/10.5849/jof.2016-043R2

Long, J. W., \& Lake, F. K. (2018). Escaping Social-Ecological Traps through Tribal Stewardship on National Forest Lands in the Pacific Northwest, United States of America. Ecology and Society, 23, Article No. 10. https://doi.org/10.5751/ES-10041-230210

Marchand, M. E., Vogt, K. A., Cawston, R., Tovey, J. D., McCoy, J., Maryboy, N. et al. (2020). The Medicine Wheel: Environmental Decision-Making Process of Indigenous Peoples. Michigan State University Press. https://doi.org/10.14321/j.ctvs89d9n

Mason, L., White, G., Morishima, G., Alvarado, E., Andrew, L., Clark, F. et al. (2012). Listening and Learning from Traditional Knowledge and Western Science: A Dialogue on Contemporary Challenges of Forest Health and Wildfire. Journal of Forestry, 110, 187-193. https://doi.org/10.5849/jof.11-006

Meyer, J. W., \& Rowan, B. (1977). Institutionalized Organizations: Formal Structure as Myth and Ceremony. American Journal of Sociology, 83, 340-363.

https://doi.org/10.1086/226550

NWCG.gov (National Wildfire Coordinating Group). https://www.nwcg.gov/ 
Pyne, S. (1982). Fire in America: "A cultural History of Wildland and Rural Fire”. Princeton University Press.

Schultz, C. A., Thompson, M. P., \& McCaffrey, S. M. (2019). Forest Service Fire Management and the Elusiveness of Change. Fire Ecology, 15, Article No. 13. https://doi.org/10.1186/s42408-019-0028-x

Steelman, T., \& Nowell, B. (2019). Evidence of Effectiveness in the Cohesive Strategy: Measuring and Improving Wildfire Response. International Journal of Wildland Fire, 28, 267-274. https://doi.org/10.1071/WF18136

Tardivo, M. L., Caymes-Scutari, P., Bianchini, G., Méndez-Garabetti, M., Cencerrado, A., \& Cortés, A. (2017). A Comparative Study of Evolutionary Statistical Methods for Uncertainty Reduction in Forest Fire Propagation Prediction. Procedia Computer Science, 108, 2018-2027. https://doi.org/10.1016/j.procs.2017.05.252

USDA (US Department of Agriculture) (2001). Fire Management Today: Fire Policy Update (Vol. 61). US Department of Agriculture.

USDA (US Department of Agriculture)/DOI (US Department of the Interior) (2009). Guidance for Implementation of Federal Wildland Fire Management Policy. US Department of Agriculture and US Department of the Interior.

USDA (US Department of Agriculture)/DOI (US Department of the Interior) (2014). National Cohesive Wildland Fire Management Strategy.

https://www.forestsandrangelands.gov/strategy/thestrategy.shtml

USDA/DOI Forests and Rangelands. Wildland Fire Leadership Council. https://www.forestsandrangelands.gov/leadership/index.shtml

USDOI (US Department of the Interior) (1995). Federal Wildland Fire Management: Policy and Program Review. US Department of the Interior, US Department of Agriculture.

USFS (US Department of Agriculture, Forest Service) (2011). National Forest System Land Management. US Department of Agriculture, Forest Service.

Zackrisson, O., Nilsson, M. C., \& Wardle, D. A. (1996). Key Ecological Function of Charcoal from Wildfire in the Boreal Forest. Oikos, 77, 10-19.

https://doi.org/10.2307/3545580 